\title{
Blood Vascular Beds of Rat Adrenal and Accessory Adrenal Glands, with Special Reference to the Corticomedullary Portal System : A Further Scanning Electron Microscopic Study of Corrosion Casts and Tissue Specimens
}

\author{
Takuro Murakami, Hideki Oukouchi, Yoshifumi Uno, Aiji Ohtsuka and Takehito Taguchi \\ Department of Anatomy, Okayama University School of Medicine, Okayama, Japan
}

Received January 13, 1989

\begin{abstract}
Summary. Blood vascular casts of the rat adrenal glands were observed with a scanning electron microscope. The cortical capillary plexus drains, through the corticomedullary venous radicles, into the subcortical veins continuous with the medullary collecting veins. The medullary capillary plexus drains into the corticomedullary venous radicles, subcortical veins and medullary collecting veins. No portal vessel was noted between the cortical and medullary capillaries. These findings indicate that the cortical blood rich in glucocorticoids preferentially and continuously flows into the corticomedullary venous radicles, subcortical veins and medullary collecting veins all three of which are fenestrated in type, and also suggest that the vascular route from the cortical capillaries to the medullary collecting veins functions as a substitute for the portal system, controling the biosynthesis of catecholamines in the adrenal medulla. The vascular bed of the accessory adrenal gland (extra-adrenal cortical or chromaffin body) is sometimes annexed to that of the adrenal gland. On rare occasions, the vascular beds of the extra-adrenal cortical and chromaffin bodies fuse with each other. Additional scanning of tissue samples confirmed the direct drainage of cortical capillaries into the medullary veins and also the endothelial fenestrations of these capillaries and veins.
\end{abstract}

Biological experiments have shown that high concentrations of glucocorticoids activate phenylethanolamine- $\mathrm{N}$-methyl transferase which converts noradrenaline to adrenaline (WURTMAN and AXELROD, 1966; POHORECKY and WURTMAN, 1971). This fact engendered the widely accepted hypothesis that glucocorticoids synthetized in the adrenal cortex control the biosynthesis of adrenaline in the adrenal medulla
(COUPland and McDougall, 1966; Martin, 1985; FAWCETT, 1986). This view has been further strengthened by some morphologists proposing that the cortical control over the medulla is mediated by special or portal blood vessels (COUPLAND and MACDOUGALL, 1966; HENDERSON and DANIEL, 1978; FAWCETT, 1986).

The blood vascular bed of the adrenal gland has been studied by light microscopic methods in various animals, including the rat. However, details of the vascular arrangements or connections between the adrenal cortex and medulla have been the subject of controversy. Early studies reported no portal route between the adrenal cortex and medulla (FLINT, 1900; BENNETT and KILHAM, 1940; GERSH and GROLLMAN, 1941). Later, some authors advocated a portal route from the cortex to the medulla (POHORECKY and Wurtman, 1971; HeNDERSON and DANIEL, 1978), whereas others denied its existence (DEMPSTER, 1974; Coupland, 1975; Coupland and SElby, 1976).

Our previous scanning electron microscope observations of vascular casts of rat adrenal glands have supported the descriptions of FLINT (1900) and others (BENNETT and KILHAM, 1940; GERSH and GROLLMAN, 1941; Dempster, 1974; Coupland, 1975; Coupland and SELBY, 1976), and indicated that the cortical capillaries preferentially drain through the corticomedullary venous radicles into the medullary veins (MURAKAMI, 1975b; KIKUTA and MURAKAMI, 1982; MURAKAMI et al., 1983). In the present study, we reinvestigate the blood vascular beds of the rat adrenal glands by the same vascular casting/scanning electron microscope method and supplement our previous findings (MURAKAMI, 1975b; KIKUTA and MURAKAMI, 1982; MURAKAMI et al., 1983). Some scanning findings 
obtained from the cationic iron colloid/polyethylene glycol/tannin/osmium-impregnated adrenal blood vessels are also included. Related findings on the replicated blood vasculatures of the accessory adrenal glands have been published elsewhere (MURAKAMI et al., 1988a, b).

\section{MATERIALS AND METHODS}

Adult male Wistar rats weighing $200-300 \mathrm{~g}$ were anesthetized with diethyl ether. They were perfused through the thoracic aorta with physiological saline and with a laboratory-prepared low viscosity methyl methacrylate casting medium (MURAKAMI, 1975a) or a commercially available Mercox medium (Mercox 2B or 2R, Oken Shoji Co., 6-12-17 Ginza, Chuo-ku, Tokyo). Prior to the perfusion, 7 parts of the Mercox medium was diluted with 3 parts of a methyl methacrylate monomer (Katayama Chemical Co., 3-7 Doshu-cho, Higashi-ku, Osaka).

The animals were then placed for about $3 \mathrm{~h}$ in a hot water bath $\left(60^{\circ} \mathrm{C}\right)$, corroded overnight or longer in a hot $10 \% \mathrm{NaOH}$ or $\mathrm{KOH}$ solution, and washed over-

Table 1. Abbreviations used in Figures 1-11

$A A$ Adrenal artery from the abdominal aorta.

$A C$ Adrenal cortex or its capillary bed.

$A G \quad$ Vascular bed of the adrenal gland.

$A M$ Adrenal medulla or its capillary bed

$A V$ Adrenal vein.

AT Vascular bed of the periadrenal adipose tissue (dissected remnant).

CS Cortical surface or its capillary plexus (cortical surface capillary plexus).

EC Vascular bed of the extra-adrenal cortical body.

$E M$ Vascular bed of the extra-adrenal chromaffin (medullary) body.

IA Adrenal artery from the inferior phrenic artery.

$M V$ Medullary central vein.

$R A$ Adrenal artery from the renal artery.

$T B$ Thick branch of the medullary central vein.

$Z F \quad$ Zona fasciculata or its capillary plexus.

$Z G \quad$ Zona glomerulosa or its capillary plexus.

$Z R \quad$ Zona reticularis or its capillary plexus.

$E C A$ Vascular bed of the extra-adrenal cortical body, which is adhered to that of the adrenal gland.

ECM Vascular bed of the extra-adrenal corticomedullary complex.

EMA Vascular bed of the extra-adrenal chromaffin (medullary) body, which is adhered to that of the adrenal gland.

$I P V$ Inferior periadrenal vein.
$M P V$ Medial periadrenal vein.

aa Proper adrenal artery.

an Arteriolo-arteriolar anastomosis in the cortical surface.

av Accessory adrenal vein.

ca Cortical artery.

cr Corticomedullary venous radicle.

$d a \quad$ Deep cortical artery.

$d d$ Direct drainage of medullary capillary into the cortical capillary in the zona reticularis.

$d r \quad$ Deep cortical venous radicle.

$d v \quad$ Deep cortical vein.

$h v \quad$ Unusual or heterotopic cortical surface vein.

la Looped cortical artery.

ma Medullary artery or its branch.

$m r \quad$ Medullary venous radicle.

$m v \quad$ Medullary collecting vein.

pa Periadrenal artery supplying the periadrenal adipose tissue.

pr Perimedullary venous radicle.

pv Periadrenal venous branch originating in the periadrenal adipose tissue.

sv Subcortical vein.

uv Usual cortical surface vein.

* Artifacts including dissected fragments of cast, defects in resin caused by blebs, macerated remnants of tissue elements and leakages of resin.

Fig. 1. Overview of the methacrylate cast of the blood vascular bed $(A G)$ from the left adrenal gland of an adult rat (viewed from an anterior aspect). Note that the blood vessels of the adrenal gland are completely reproduced. Note also the vascular cast of the extra-adrenal chromaffin body $(E M A)$ being adhered to that of the adrenal gland. Inset shows a closer view of the cortical surface capillary plexus (CS). Thick arrow Medullary artery, thin arrow arteriolo-arteriolar anastomosis, thick arrowhead deep cortical vein, thin arrowhead recurrent surface branch derived from the looped cortical artery indicated by double arrowheads, double arrows deep cortical artery. For other abbreviations, are Table $1 . \times 60$, Inset: $\times 120$ 


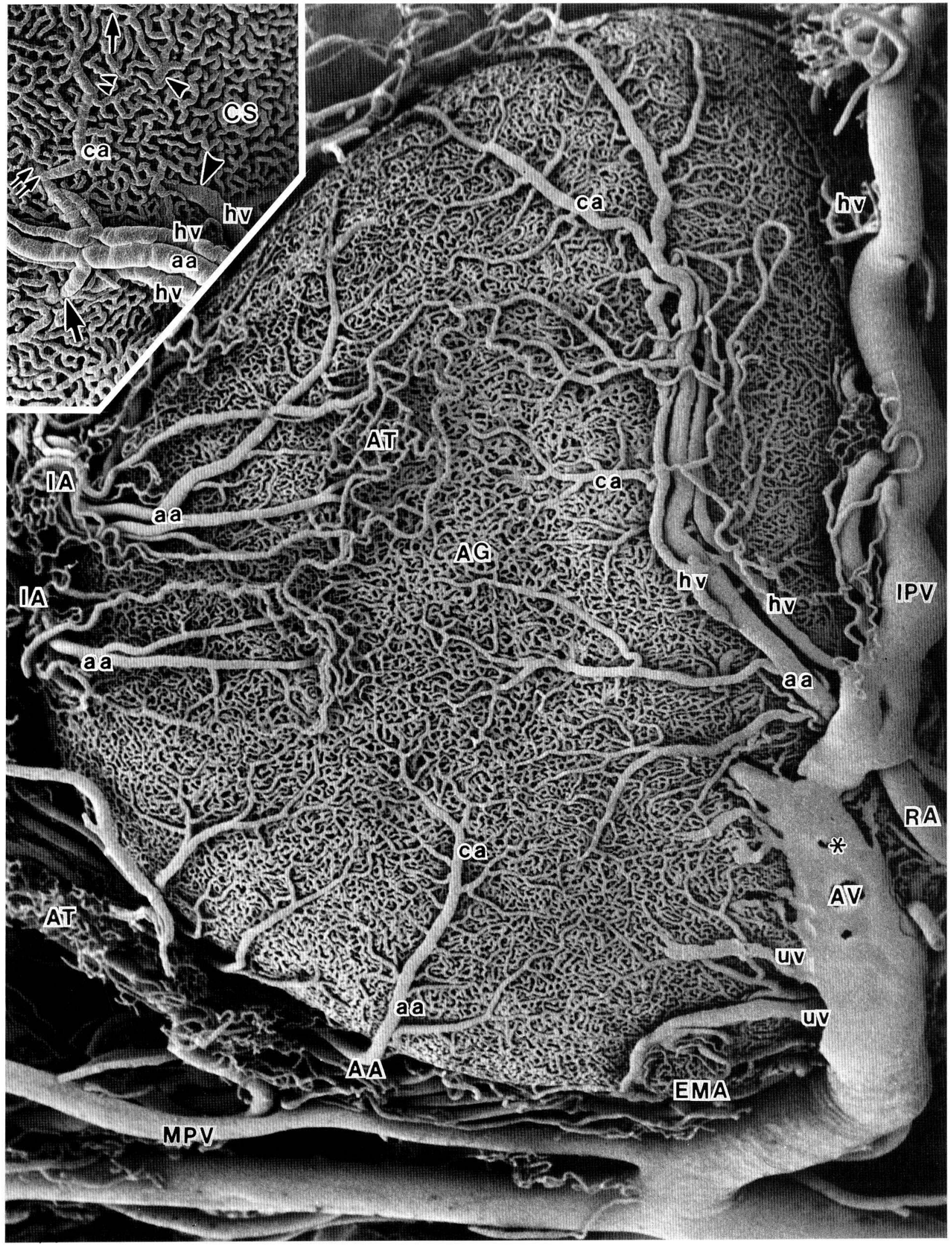

Fig. 1. Legend on the opposite page. 
night or longer in running tap water. The blood vascular casts of the adrenal and accessory adrenal glands thus prepared were air-dried, coated with gold in a vacuum evaporator, and observed with a scanning electron microscope (HHS-2R, Hitachi) using an acceleration voltage of $5 \mathrm{kV}$. After scanning, the casts were freeze-cut with razor blades or dissected with sharpened forceps or needles under a stereomicroscope (SMZ-10, Nikon) and again observed with the scanning electron microscope. This series of dis-

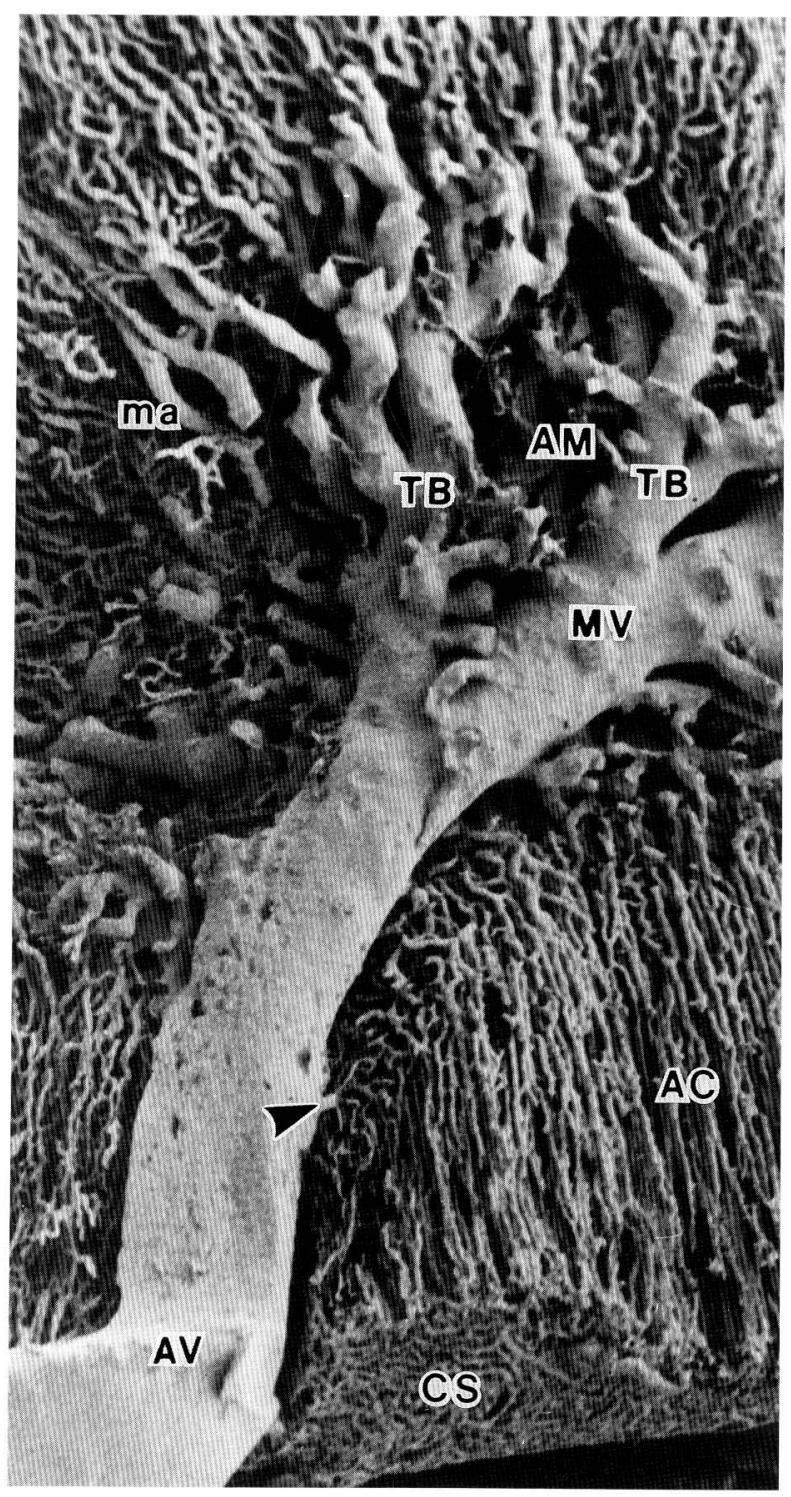

Fig. 2. A dissected cast of the left adrenal gland. The medullary central vein $(M V)$ receives cortical $(A C)$ and medullary $(A M)$ vessels and drains into the adrenal vein $(A V)$. Arrowhead indicates a deep cortical venous radicle. $\times 80$ section and scanning of the casts was repeated for thorough visualization of the inner structures of the casts.

As additional experiments, some of the salineperfused adrenal glands were fixed by arterial infusion of $2 \%$ glutaraldehyde in $0.1 \mathrm{M}$ phosphate buffer. They were cut with razor blades into thin slices with a thickness of $0.5-1.0 \mathrm{~mm}$, fixed again in the buffered glutaraldehyde solution for $6 \mathrm{~h}$ or longer, and treated with cationic iron colloid, polyethylene glycol, tannic acid and osmium tetroxide (OHTSUKA and MURA KAMI, 1988). The slices were then freeze-cracked in liquid nitrogen (IIDA, 1984), freeze-dried with tertiary butanol (WhEELER et al., 1975; INOUE and OSATAKE, 1988), and observed with the scanning electron microscope using an accelaration voltage of $20 \mathrm{kV}$.

\section{RESULTS}

Sufficient infusion of a low viscosity methacrylate or diluted Mercox casting medium through the thoratic aorta produced satisfactory vascular casts of the adrenal and accessory adrenal glands (Figs. 1-9). Leakage of the infused resin was negligible, if at all (Figs. 4, 7, 8). Remnants after maceration of tissue elements were equally uncommon and sporadic (Fig. 8). Repeated microdissections of the casts each time followed by scanning allowed a detailed analysis of the blood vascular beds of the adrenal and accessory adrenal glands (Figs. 2-9).

In the rat, the blood vascular beds of the adrenal glands were more or less ovoid in shape (Fig. 1) though the right one was somewhat smaller than the left one. Regardless of their sizes, the vascular beds of the right and left adrenal glands were similar in structure and organization.

On each side, the adrenal arteries arose from the inferior phrenic artery, abdominal aorta and renal artery (Fig. 1). They branched into finer arteries as they approached the adrenal gland (Fig. 1). Their final branches, the proper adrenal arteries, reached the surface of the gland from the superior, medial and inferior aspects (Fig. 1), and ran on the surface to give off cortical and medullary arteries of the adrenal gland (Figs. 1, 3, 7).

The adrenal arteries, on their way, gave off many periadrenal arteries which continued into the capillary bed of the periadrenal adipose tissue (Fig. 1). This vascular bed drained into the medial, superior and inferior periadrenal veins, which ran along the medial, superior and antero-lower borders of the adrenal gland, respectively (Fig. 1). The superior 
periadrenal vein drained into the inferior phrenic vein. The medial and inferior periadrenal veins drained into the adrenal vein (Fig. 1).

The cortical arteries divided on the surface of the adrenal gland, and continued into the cortical surface capillary plexus which consisted of a single layer of freely anastomosing capillaries investing the whole adrenal gland (Fig. 1). An arteriolo-arteriolar anastomosis was sometimes noted in the cortical surface plexus (Fig. 1, Inset).

The medullary arteries were derived from the proper adrenal arteries and numbered from three to five (usually, four). They penetrated the adrenal cortex, and reached the adrenal medulla to supply the medullary capillary plexus (Figs. 1, Inset, 2-5, 7, 8). The medullary arteries were variable in thickness. Usually, one or two of them were well developed to supply upwards of two thirds of the medullary plexus (Figs. 3, 7); the remaining ones were poorly developed, merely supplying a small part of this plexus (accessory medullary arteries) (Figs. 2, 3, Inset).

Looped cortical arteries occasionally occurred as aberrant vessels. They descended in the adrenal cortex and then turned back to supply the cortical surface capillary plexus (Fig. 1, Inset; Fig. 7, Inset A and B). In typical cases, they reached as far as the corticomedullary junction (Fig. 7, Inset A). It was usual for the looped arteries on their intracortical way to give off some capillary branches which continued into the cortical capillary plexus (see below) (Fig. 7, Inset B). On rare occasions, a looped vessel divided in the cortex into four or more branches. In these cases, one or two branches descended as medullary arteries into the medulla, whereas the other ones turned back to continue into the cortical surface capillary plexus (Fig. 7, Inset A).

Deep cortical arteries also occasionally occurred as aberrant vessels. They descended rather directly in the adrenal cortex and continued into the capillaries of the zona fasciculata (see below) (Fig. 1, Inset; Fig. 8 , Inset). It was rather rare for these deep cortical arteries to reach the zona reticularis. On rare occasions, the deep cortical arteries were very short and only supplied the zona glomerulosa.

Capillaries of the cortical surface were sinusoidal in nature (Fig. 1, Inset). They were anastomosed with each other and organized into the cortical capillary plexus (Fig. 2). This capillary plexus continuously supplied the zona glomerulosa, fasciculata and reticularis, and tended to be arranged in accordance with the histological patterns of the zones. The capillaries were arranged like round baskets in the zone glomerulosa, in centripetal pallisades in the zona fasciculata, and rather tortuously in the zona reticularis (Figs. 2, 4, 5).

The sinusoidal capillaries thus passing the adrenal cortex converged at the corticomedullary junction into the corticomedullary venous radicles which were fairly independent and grouped vessels running into the adrenal medulla (Figs. 4-6). Usually, 10 to 20 cortical capillaries in the zona reticularis gathered to form a venous radicle (Figs. 5, 6). Few cortical capillaries were connected to the medullary capillaries.

The medullary arteries, including those arising from the looped cortical arteries (see above), branched in the adrenal medulla and gave rise to freely anastomosing capillaries which formed the medullary

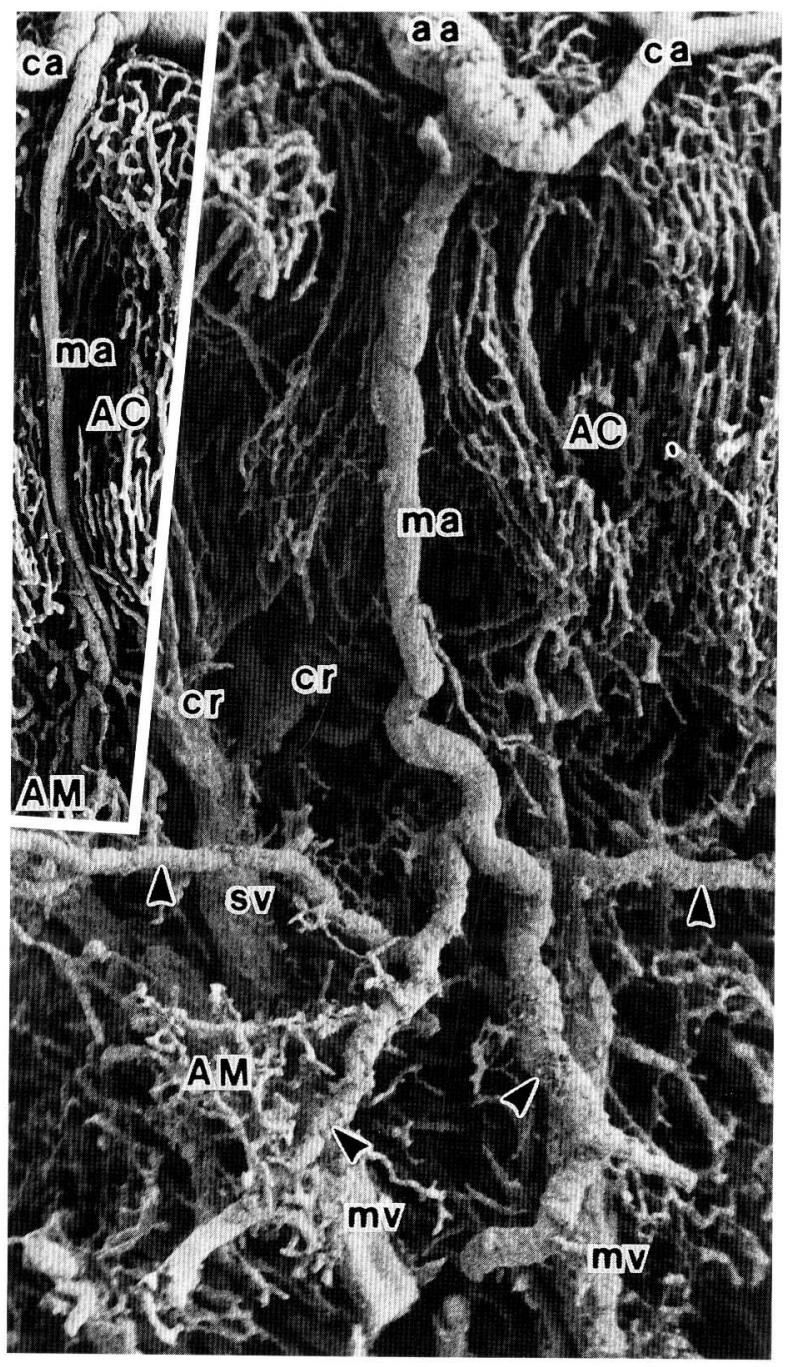

Fig. 3. A well developed medullary artery $(m a)$ and its branches (arrowheads). Inset shows a poorly developed medullary artery ( $m a$ ) (accessory medullary artery). $\times 100$, Inset: $\times 80$ 
plexus (Figs. 3-5). This plexus extended in the medulla and was markedly coarser in mesh than that of the cortex (Figs. 4, 5). The capillaries of the medullary plexus were not sinusoidal and were thinner than the cortical capillaries (Fig. 5). The medullary capillaries converged into the medullary venous radicles which were distributed within the medulla (see below) (Figs. $4,5)$.

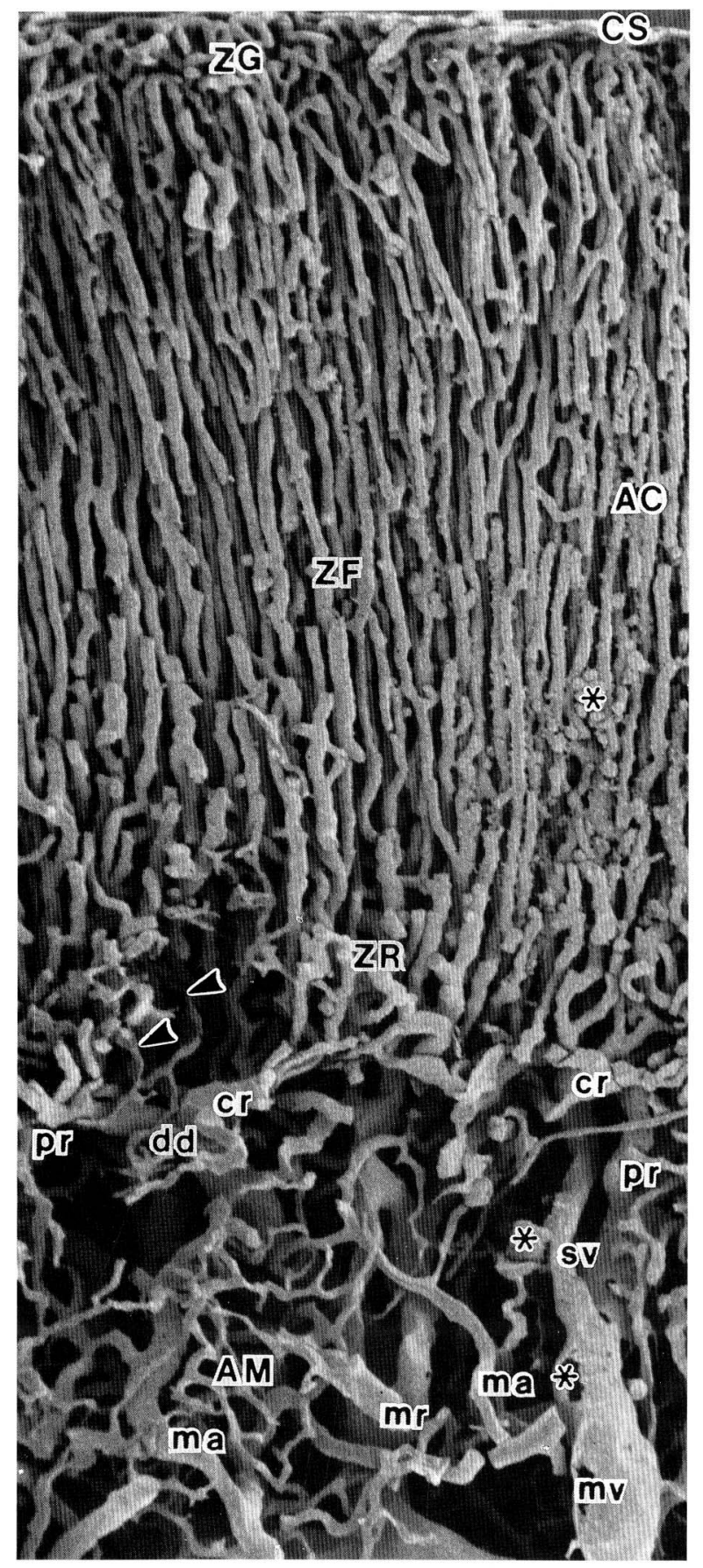

The medullary capillaries near the corticomedullary junction showed a particular pattern in their drainage. Most of them converged, beneath the corticomedullary junction, into small venous radicles (perimedullary venous radicles) which drained into the corticomedullary venous radicles or subcortical veins (see below), while a few of them ascended into the zona reticularis, and directly continued into the cortical capillaries (more strictly, the terminal capillaries in the zona reticularis) which drained into the corticomedullary venous radicles (a direct drainage of medullary capillary into the cortical capillary) (Figs. 4, 5).

The corticomedullary venous radicles, thus receiving the cortical capillaries and perimedullary venous radicles, converged, at the subcortical layers of the medulla, into the subcortical veins (Figs. 4-6). These veins ran centripetally in the adrenal medulla and anastomosed with each other in a tree-like pattern (Figs. 4, 5). They also received the medullary venous radicles (see above) and finally drained, as the medullary collecting veins, into the thick branches of the medullary central vein which ran rather eccentrically along the lower border of the adrenal medulla (Figs. $2,4,5)$. The medullary venous radicles in the central regions of the medulla formed several thin venous trunks which directly drained into the medullary collecting veins or into the thick branches of the medullary central vein (Figs. 4, 5).

The medullary central vein emerged, as the adrenal vein, the hilus of the adrenlal gland (Figs. 1, 2). On its way from the medulla to the cortical surface, the medullary central vein or adrenal vein received up to several venules (deep cortical venous radicles) from the cortical capillaries around it (Fig. 2).

Fig. 4. A freeze-cut and dissected adrenal cast. The cortical vascular bed $(A C)$ formed by the continuous capillary plexuses of the cortical surface $(C S)$, zona glomerulosa $(Z G)$, zona fasciculata $(Z F)$ and zona reticularis $(Z R)$ confluences into the corticomedullary venous radicles $(c r)$ which drain into the subcortical veins $(s v)$ and medullary collecting veins $(m v)$. The medullary capillaries $(A M)$ derived from the medullary arteries $(m a)$ drain, as the perimedullary $(p r)$ or medullary $(m r)$ venous radicles, into the corticomedullary venous radicles, subcortical veins, medullary collecting veins or thicker veins. Futhermore, note that a medullary capillary $(d d)$ runs into the zona reticularis and branches into two capillaries to drain into the terminal capillaries of the zona reticularis (arrowhead) (direct drainage of medullary capillary into the cortical capillary). $\times 150$ 
Some cortical surface veins were constantly formed near the hilus from the cortical surface capillary plexus (usual cortical surface veins) (Fig. 1). These veins continued, in the hilus region of the adrenal gland, into the adrenal vein (Fig. 1). On some occasions, a few cortical surface veins (unusual or heterotopic cortical surface veins) arose from the cortical surface capillary plexus in the anterior or anterolateral regions of the adrenal gland and drained into the inferior periadrenal vein (see above) (Fig. 1).

On rare occasions, deep cortical veins occurred as aberrant vessels. They arose from the capillaries in the zona fasciculata and ascended rather straightly in the adrenal cortex to continue into the usual or unusual cortical surface veins (see above) (Figs. 1, Inset, 8). On their way to the adrenal surface, they received the capillaries in the zona glomerulosa (Fig. 8). It was rather rare for the deep cortical veins to originate in the capillaries in the zona reticularis. Short-ranged deep cortical veins received only the capillaries in the zona glomerulosa and those in the upper end of the zona fasciculata.

One or two accessory adrenal veins rarely arose from the subcortical or medullary collecting veins in the medulla and penetrated the cortex, to emerge on the surface of the adrenal gland and to continue into the usual or unusual cortical surface veins (see above) (Fig. 7). When fully developed, the accessory adrenal veins were as thick as the adrenal vein (Fig. 7). Each of the accessory adrenal veins was fairly independent; the subcortical or medullary collecting veins continuous with an accessory vein had few communications with those draining into the adrenal vein or other accessory vein (Fig. 7).

The adrenal vein, thus collecting the medullary central vein, cortical surface veins and accessory veins (see above), received the medial and inferior periadrenal veins (see above) and drained into the renal vein (left side) or vena cava inferior (right side).

One to five accessory adrenal glands (extra-adrenal cortical or chromaffin bodies) of various sizes and shapes were frequently noted near the adrenal vein or around the adrenal gland (Fig. 9). The cortical bodies contained sinusoidal capillaries (Fig. 9), whereas the chromaffin bodies contained fine capillaries (Fig. 9, Inset A). On rare occasions, these cortical or chromaffin bodies were clustered (Fig. 9 and Inset A). Regardless of its size, shape and position, each cortical or chromaffin body received one or occasionally two afferent vessels from the branches of the renal artery or abdominal aorta and issued one or occasinally two efferent vessels continuous with the medial periadrenal, inferior periadrenal or adrenal vein. The vascular bed of the cortical or chromaffin body was occasionally adhered to that of the adrenal gland. This adhesion was seen as a protrusion from the surface capillary plexus of the main gland (Figs. $1,7,9)$.

Very rarely, the vascular beds of the extra-adrenal cortical and chromaffin bodies were fused with each other. In these cases, the vascular bed of the

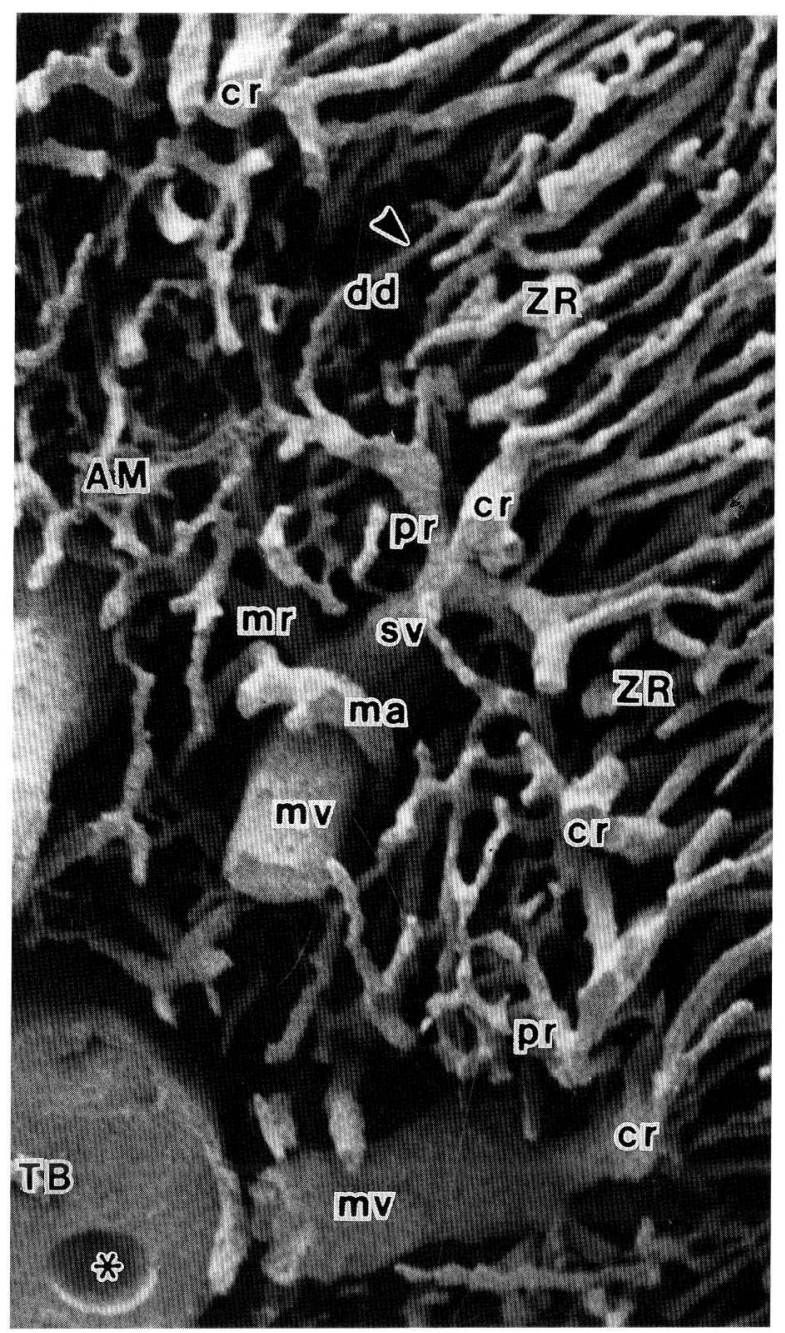

Fig. 5. Another example of freeze-cut and dissected adrenal cast, showing the confluence of cortical capillaries (capillaries in the zona reticularis, $Z R$ ) into the corticomedullary venous radicles $(c r)$ continuous with the subcortical $(c v)$ and medullary collecting $(m v)$ veins. The perimedullary $(p r)$ and medullary $(m r)$ venous radicles collecting the medullary capillaries $(A M)$ and draining into the corticomedullary venous radicles, subcortical veins or medullary collecting veins are seen. A direct drainage of medullary capillary into the cortical capillary is also seen ( $d d$ or arrowhead). $\times 130$ 


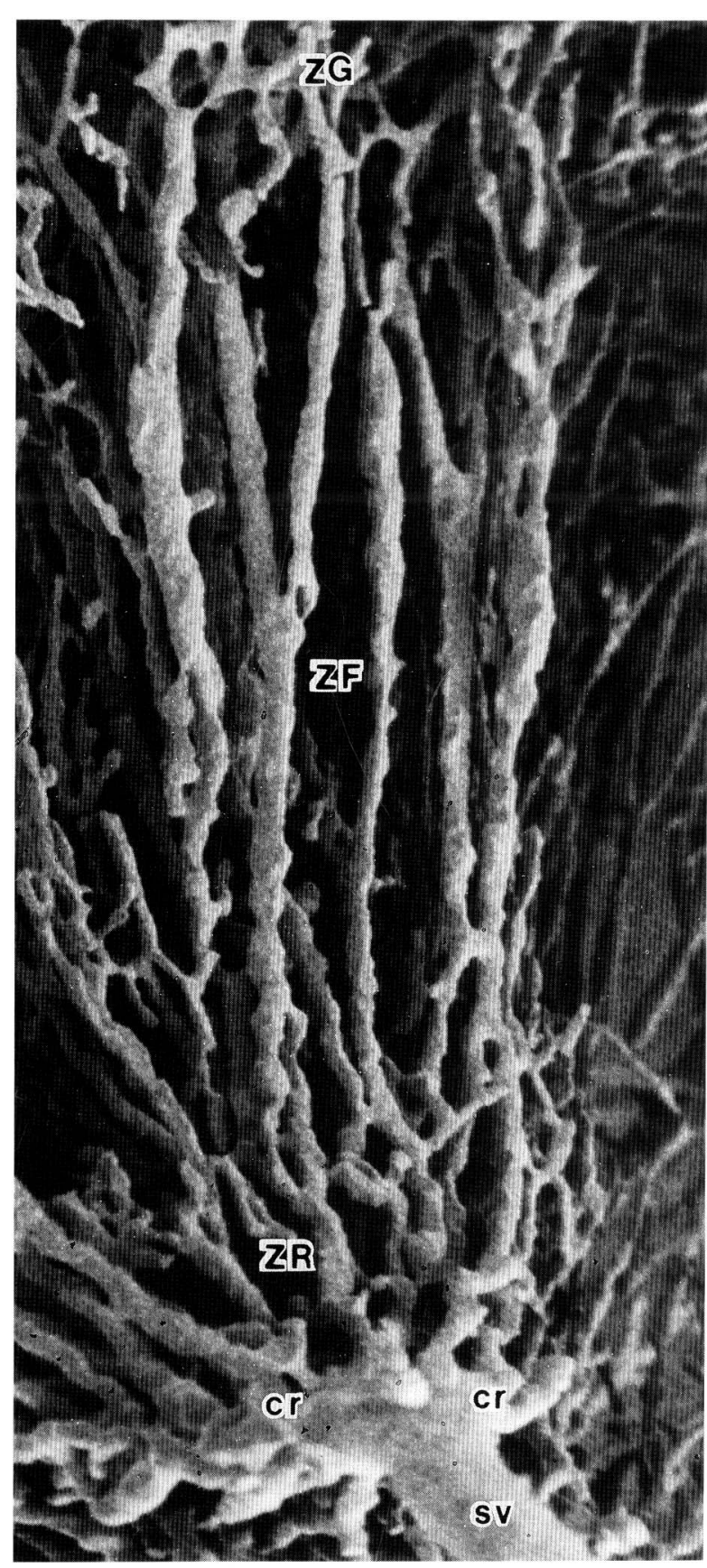

Fig. 6. Isolated corticomedullary venous radicles $(\mathrm{cr})$ and their connecting cortical capillaries $(Z F, Z G, Z R)$ and subcortical vein $(s v) . \times 200$ chromaffin body was completely or partially enclosed by that of the cortical body (Fig. 9). Such an extraadrenal corticomedullary capliiary complex received either a single or two afferent vessels from a branch of the renal artery (Fig. 9, Inset B) and issued either a single or two efferent vessels continuous with a branch of the adrenal vein. When the complex was provided with two afferent and two efferent vessels, the cortical and chromaffin parts of the complex were supplied separately by them.

Neither a valvular impression nor an endothelial constriction was imprinted in any segments of the adrenal and extra-adrenal vascular systems, including the adrenal arteries and veins and the extraadrenal afferent and efferent vessels.

The above described findings are schematically diagrammed in Figure 10. Aberrant vessels are in cluded in this diagram.

Additional scanning electron microscopy of perfusion-fixed, cationic iron colloid/polyethylene glycol/ tannin/osmium-impregnated and freeze-cracked adrenal tissues confirmed the preferential and direct drainage of cortical capillaries into the corticomedullary venous radicles continuous with the subcortical and medullary collecting veins (Fig. 11). It also confirmed the endothelial fenestrations of the subcortical and medullary collecting veins as well as the cortical capillaries and corticomedullary venous radicles (Fig. 11, Insets A-D). In these cortical capillaries and medullary veins, the fenestrations were similar in sizes, shapes and distributions; they were constantly observed as round or ovoid micropores with approximately 40-50 nm diameters and with exclusive and clustered distribution in the attenuated areas of the endothelium. Such fenestrations abruptly disappeared at the end of the medullary collecting vein. No fenestration thus was noted in any segments of the medullary central vein and its thick branches (Fig. 11, Inset $\mathrm{E})$.

\section{DISCUSSION}

Together with our previous ones (MURAKAMI, 1975b; KiKuTA and Murakami, 1982; Murakami et al., 1983), the present scanning study of corrosion casts evidences that in the rat adrenal gland, essentially all

Fig. 7. An adrenal vascular bed issuing two efferent vesseles ( $A V$ and $a v)$. A fusion of the vascular beds of the adrenal gland and extra-adrenal cortical body is seen (ECA). The vessels indicated by arrowheads were continuous. Inset A shows a looped cortical artery (la) which issues four or more surface recurrent branches (thick arrowheads) and a medullary artery $(m a)$. Inset B shows another looped artery $(l a)$ with some cortical capillary branches (thin arrowheads). $\times 60$, Inset $A: \times 90$, Inset B: $\times 40$ 


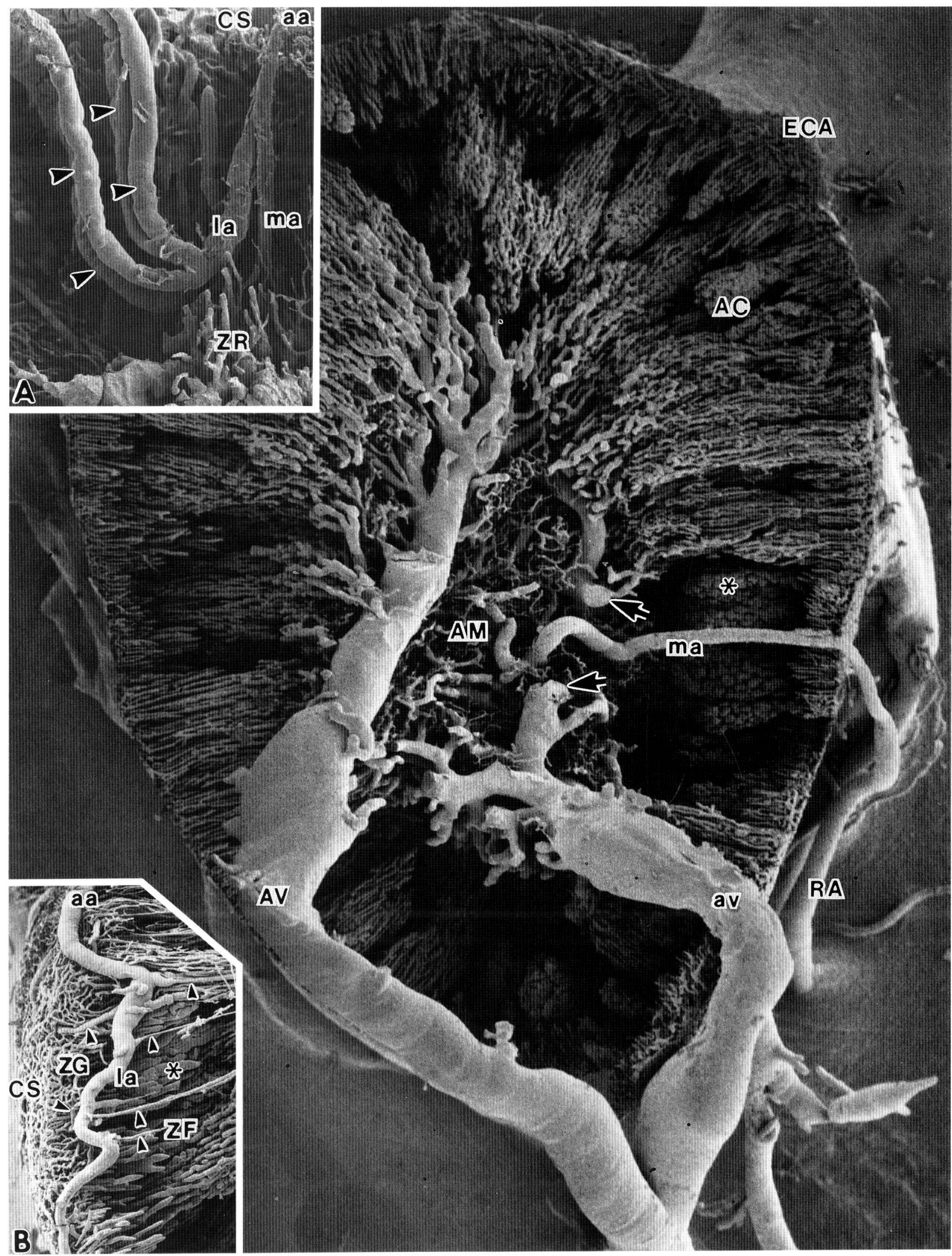

Fig. 7. Legend on the opposite page. 


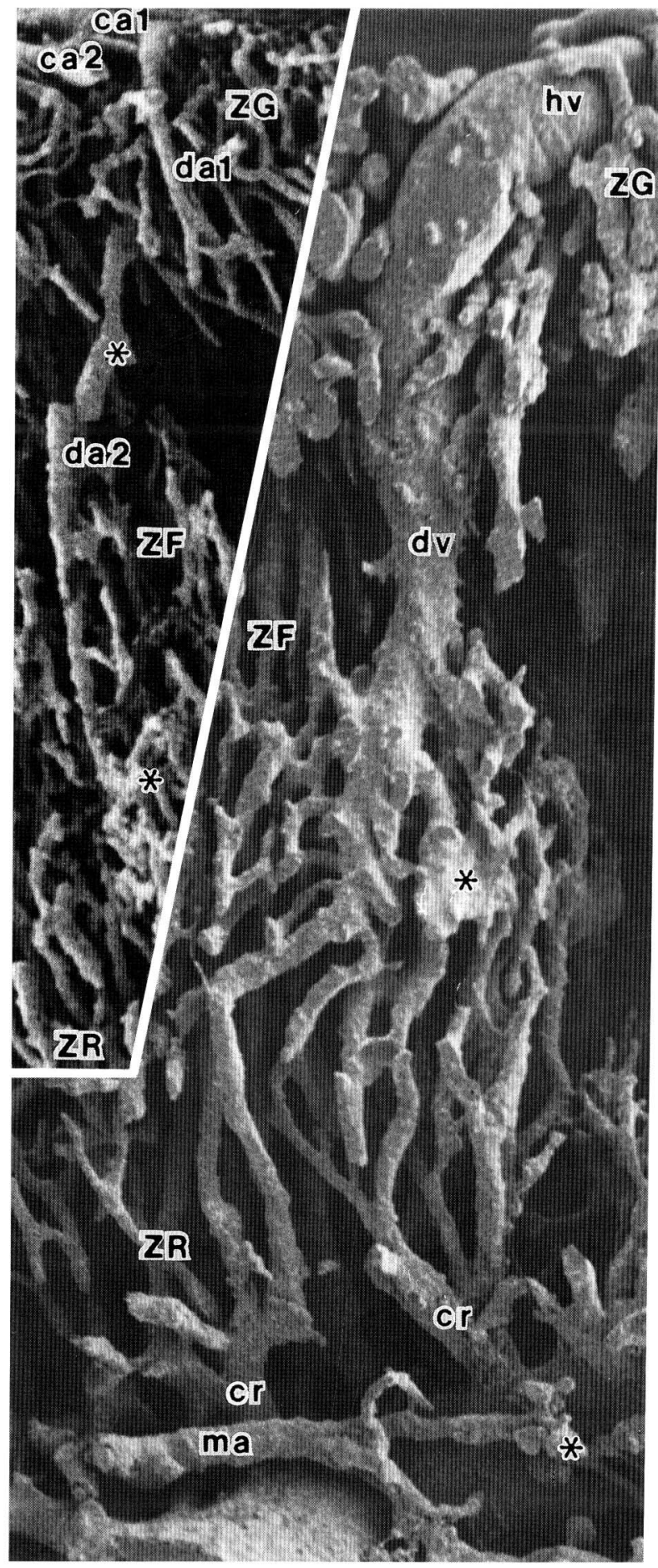

Fig. 8. A well developed deep cortical vein $(d v)$ which originates deep in the zona fasciculata $(Z F)$. The inset shows two deep cortical arteries (da1 and da2) which arise from the ca1 and ca2 cortical surface arteries, respectively. $\times 150$, Inset: $\times 115$ cortical capillaries derived from the cortical arteries flow, through the corticomedullary venous radicles, subcortical veins and medullary collecting veins, into the medullary central vein continuous with the adrenal vein. It is also shown that the medullary plexus is a fairly independent network which originates in the medullary arteries and drains, through the corticomedullary, perimedullary and medullary venous radicles and through the subcortical and medullary collecting veins, into the medullary central vein. The present study thus confirms anew that in the rat adrenal gland, no portal vessel exists between the cortical and medullary capillary plexuses. Many authors have reached similar results in man and various animals, including the rat, by conventional light microscopic methods mainly using India inkinjected tissues (Flint, 1900; BENnETT and Kilham, 1940; Gersh and Grollman, 1941; Lever, 1952; EZAKI, 1958; Dempster, 1974; Coupland and SELby, 1976). Transmission or scanning electron microscopic observations, including the present additional one, of fixed tissues have also confirmed in the cat, rat and other animals, the direct drainage of cortical capillaries into the medullary veins (MоTTA et al., 1979; KIKUTA and MURAKAMI, 1984).

Some authors, on the other hand, have reported a portal circulation system connecting the cortical capillaries to the medullary ones (HAMILTON, 1957 cited by FAWCETT, 1986; HARRISON and HOEY, 1960), and have regarded this system as the route for corticoids regulating the biosynthesis of catecholamines in the medulla (POHORECKY and WURTMAN, 1971; HENDERSON and DANIEL, 1978; FAWCETT, 1986). However, as supported by the present and previous cast observations (MURAKAMI, 1975b; KIKUTA and MuraKAMI, 1982; MuraKAMI et al., 1983), the medullary capillaries supplying the parenchymal cells in the adrenal medulla arise directly from the medullary arteries and receive few afferent vessels from the cortical capillaries. This finding, together with those of Dempster (1974) and Coupland and Selby (1976), contradicts the concept of a corticomedullary portal circulation which would directly connect the cortical and medullary capillaries.

As discussed previously (MURAKami, 1975b; KI KUTA and MURAKAMI, 1982), attention should be paid in this context to the fact that at the corticomedullary junction, the cortical capillaries converge into the corticomedullary venous radicles which continuously drain into the subcortical veins, medullary collecting veins and medullary central vein. We believe that these radicles and subsequent veins may serve towards mediation of the cortical control over 
the medulla. In fact, our previous observations of the rat adrenal medulla by transmission electron microscopy, which clearly distinguished each medullary blood vessel by reconstruction of serial sections, have indicated that the medullary collecting veins as well as the corticomedullary venous radicles and the subcortical veins have an attenuated and fenestrated endothelium, resembling the capillary endothelium in the adenohypophysis or adrenal cortex (KIKUTA and MURAKAMI, 1984). Similar results have been obtained even by the present additional scanning observation of the rat adrenal tissue samples. Our data thus show that the corticomedullary venous radicles, subcortical veins and medullary collecting veins are enlarged sinusoidal capillaries in nature, and that the adrenal cortex and medulla are connected by the long-ranged sinusoidal vessels (cortical capillaries, corticomedullary venous radicles, subcortical veins and medullary collecting veins). Our data, moreover, suggest that the vascular or sinusoidal route from the cortical capillaries to the medullary collecting veins may function as a substitute for the portal system to carry the cortical corticoids to the medullary chromaffin cells.

Direct venous drainages from the cortical capillary plexus around the adrenal vein or near the adrenal hilus into the adrenal vein (deep cortical venous radicles or usual cortical surface veins, see above) have been reported in the cat and other animals, including the rat, by previous authors (BENNETT and Kilham, 1940; LeVer, 1952; OKANo et al., 1960) as well as the present authors (KIKUTA and MURAKAMI, 1982; MURAKAmi et al., 1988b). These drainages are scanty and limited in occurrence. Direct surface drainages from the anterior or antero-laterel regions of the adrenal gland into the inferior periadrenal vein (unusual or heterotopic cortical surface veins, see above) occur only occasionally. The deep cortical veins arising deep in the adrenal cortex and draining into the cortical surface veins are rather rare (see above). These findings may indicate that the cortical

Fig. 9. An assembly of the extra-adrenal cortical capillary beds $(E C)$ near the adrenal vein $(A V)$. One of them (arrowed $E C$ ) is continuous with the capillary protrusion $(E C A)$ of the adrenal gland $(A G)$, and contains a capillary network of extra-adrenal chromaffin body (arrowhead). Inset A shows the clustered vascular beds of extraadrenal chromaffin bodies $(E M)$. Inset $\mathbf{B}$ shows a dissected cast of the extra-adrenal corticomedullary complex $(E C M)$ with a single afferent artery $(a) . \times 110$, Inset $\mathrm{A}$ : $\times 75$, Inset $\mathrm{B}: \times 95$ blood almost exclusively and preferentially flows, through the corticomedullary venous radicles and subcortical veins, into the medullary veins.

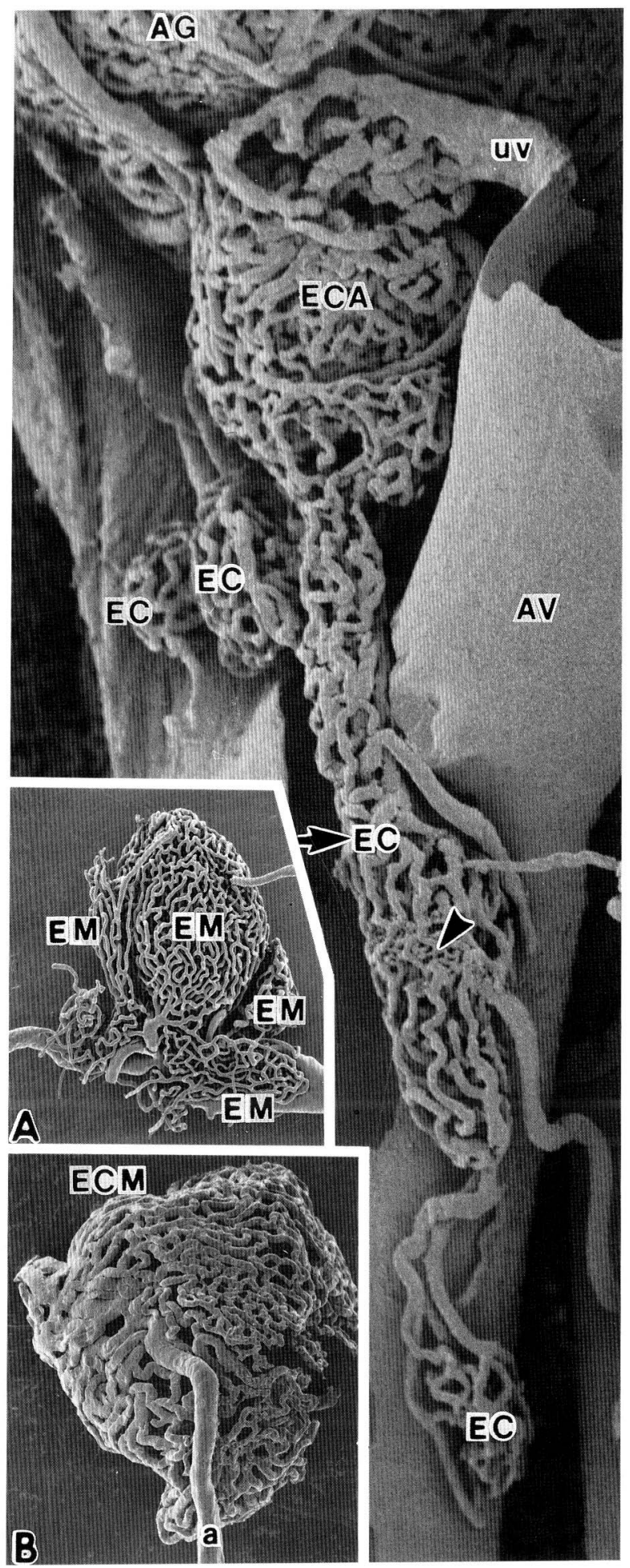


As is well known, the adrenal gland develops from two components: a mesodermal portion forming the cortex and a neuroectodermal portion forming the medulla (KEENE and HEwER, 1927; BACHMANN, 1954a; GARDNER, 1975). Parts of the mesodermal and neuroectodermal portions may remain outside the gland and survive as the extra-adrenal cortical and chromaffin bodies (WRETE, 1927; WATZKA, 1943;
Bachmann, 1954b; Coupland, 1960; Hervonen, 1971; Hervonen et al., 1978; MASCORRo et al., 1984). Although little has been known about the vasculature of these bodies, our previous scanning observations of vascular casts have demonstrated in the rat the extra-adrenal chromaffin body contains a capillary network which is denser than that of the adrenal medulla, and also that the extra-adrenal cortical

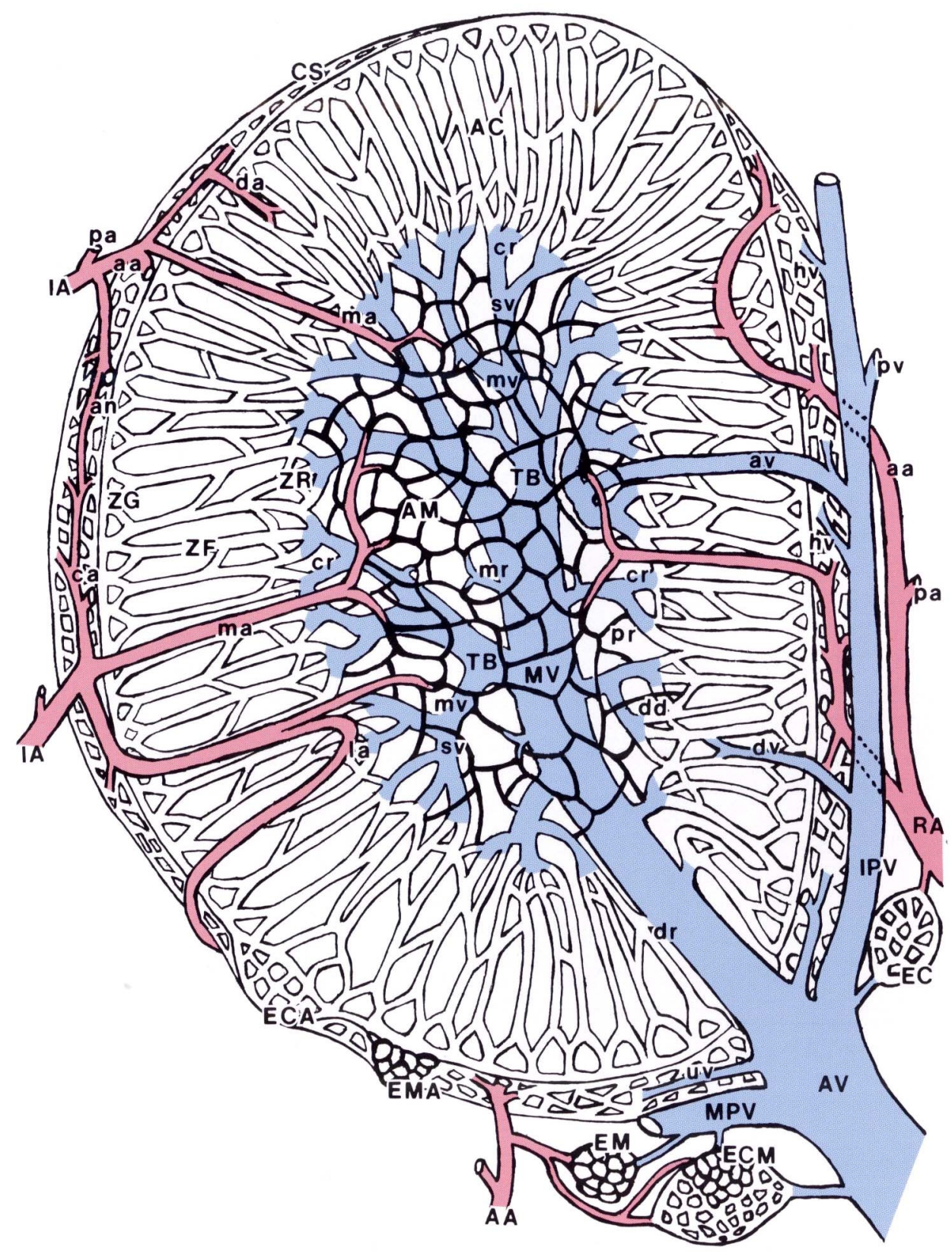

Fig. 10. A diagram showing the vascular arrangements of the rat adrenal gland. For abbreviations, see Table 1. 


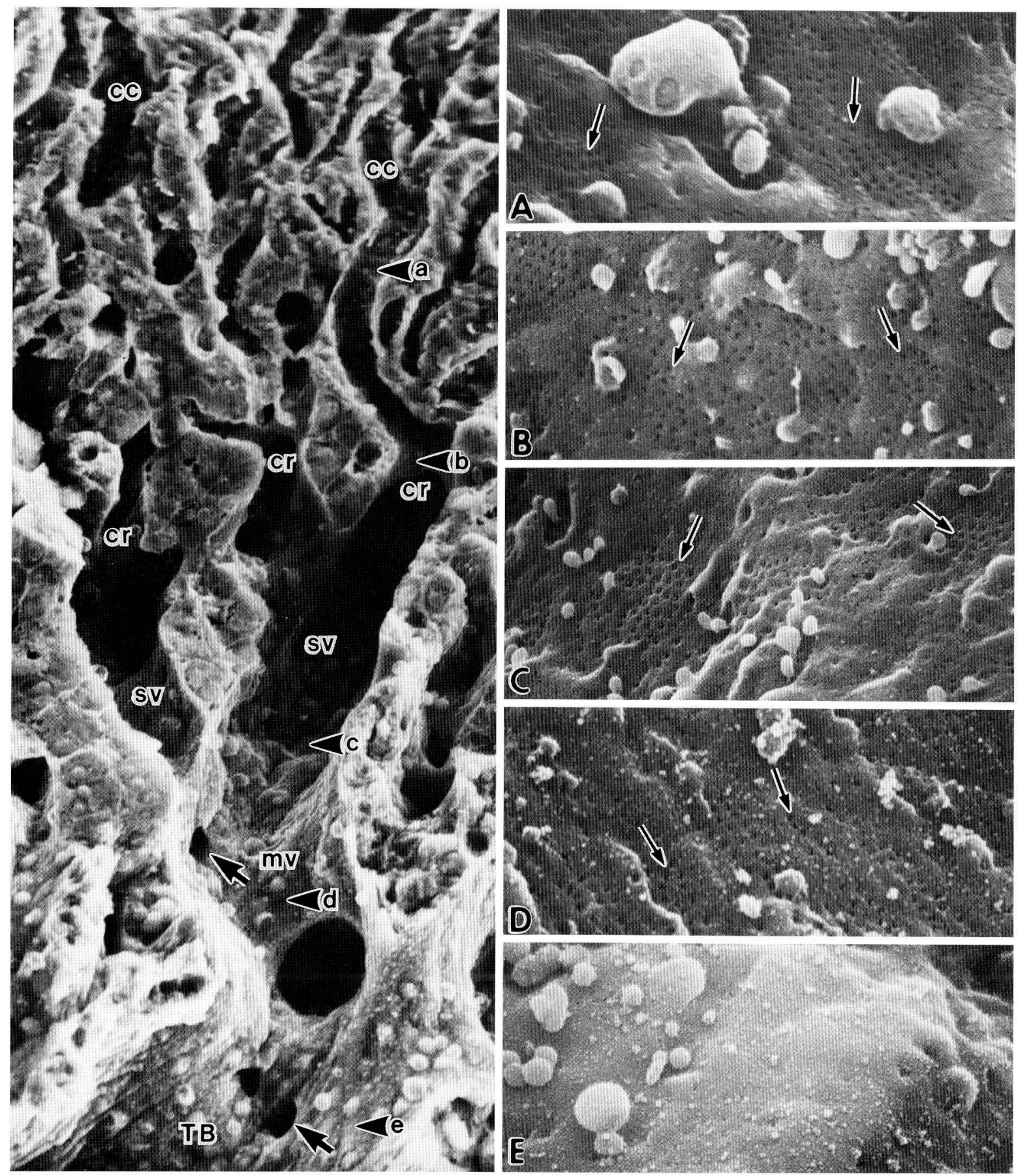

Fig. 11. A freeze-cracked surface of an adult rat adrenal tissue, confirming the direct drainage of cortical capillary $(c c)$ into the corticomedullary venous radicle $(c r)$ and subsequent subcortical $(s v)$ and medullary collecting $(m v)$ veins. Thick arrows indicate the orifices of the perimedullary or medullary venous radicles arising from the medullary capillary plexus. Insets $\mathbf{A}, \mathbf{B}, \mathbf{C}, \mathbf{D}$ and $\mathbf{E}$ show closer views of the parts indicated by the arrowheads $a, b, c, d$ and $e$, respectively. Note in these insets that the cortical capillary and its connecting medullary vein are fenestrated (arrows), whereas the medullary central vein or its thick branch $(T B)$ is not fenestrated. $\times 370$, Inset A-E: $\times 14,000$ 
body contains a rich network of sinusoidal capillaries (MURAKAMI et al., 1988a, b). The present study reconfirms these findings.

It is noteworthy that the adrenal gland rarely issues one or two accessory adrenal veins, and that the extra-adrenal cortical or chromaffin body can fuse with the adrenal gland. Our previous study of casts in the rat has demonstrated a typical efferent vessel of the extra-adrenal cortical body provided with superficial and deep branches (MURAKAMI et al., 1988b). We assume that the medullary central vein continuous with the adrenal vein is homologous with the deep branch, and that the cortical surface veins are homologous with the superficial branches (MURA KAMI et al., 1988b). We thus suppose that such an aberrant adrenal gland with two or more efferent vessels is formed by fusion of the adrenal gland with the extra-adrenal cortical bodies in the early fetal period. If the fusion of the adrenal gland and the extra-adrenal cortical body occurs at a late fetal period, the vascular bed of the latter body may remain as a surface sinusoidal capillary protrusion of the adrenal vascular bed. If the fusion of the adrenal gland and the extra-adrenal chromaffin bodies occurs at this period, the vascular beds of these bodies may remain as the surface capillary protrusions of the adrenal bed. Fusion of the adrenal gland and extraadrenal chromaffin bodies in the early fetal period may form an adrenal gland with accessory medullary arteries.

The looped cortical arteries, deep cortical arteries and deep cortical veins are also rather strange vessels whose developing mechanisms are unknown (BENNETT and KILHAM, 1940; GeRSH and GROLlman, 1941; LEVER, 1952; HARRISON and HOEY, 1960; OKANO et al., 1960; KIKUTA and MURAKAMI, 1982). However, our present and previous studies (MURAKAMI et al., 1988a, b) have shown in the rat that the extra-adrenal cortical or chromaffin body is provided with the fairly independent afferent and efferent vessels. It is presumed that, if the cortical body and its afferent and efferent vessels are taken into the adrenal gland in the early fetal period, the deep cortical vessels, including the looped arteries, may be formed. If the clustered extra-adrenal cortical and chromaffin bodies with a common arterial branch are incorporated into the adrenal gland, such a looped cortical artery with cortical and medullary branches as shown in Inset A of Figure 7 may be formed.

Of further interest is the extra-adrenal cortical and chromaffin bodies fusing with each other into an extra-adrenal corticomedullary complex. The present observation indicates that the vascular bed of the complex receives one or two afferent vessels and issues one or two efferent vessels. We expect that this pattern of blood supply is maintained even in the adrenal gland. The fact is, however, that the adrenal gland receives many afferent vessels (proper adrenal arteries) and usually issues one efferent vessel (medullary central vein or adrenal vein). To account for this, we propose that the adrenal cortex and medulla are derived from several clusters of mesodermal and neuroectodermal cells, each of which may have been provided with proper afferent and efferent vessels. We also postulate that the afferent vessels of the mesodermal and neuroectodermal cell clusters survive as the proper adrenal arteries, whereas the efferent vessels of the mesodermal and neuroectodermal cell clusters mostly disappear during the fetal period for the cortical and medullary capillaries preferentially to confluence into a single deep venous branch which may be retained as the medullary central vein or adrenal vein.

Some authors described some capsular arteries and veins in the dog and cat adrenal glands (FLINT, 1900; HAYASHI, 1959). In our present and previous studies (KiKUTA and MURAKamI, 1982), such vessels could not be identified except for those of the periadrenal adipose tissue. A few authors described or illustrated in the sheep and other animals some direct connections between the medullary arteries and veins (Russo and Pelagalli, 1972). Such arterio-venous or arteriolo-venular anastomoses were never reproduced in any areas, including the medulla and cortical surface, of the rat adrenal gland.

KATHOLI et al. (1982) reported in the dog some portal vessels connecting the adrenal gland and kidney. However, HoRACEK et al. (1985) denied the existence of such adrenorenal portal vessels upon dissecting microfil-injected specimens of the monkey under a light microscope. In accordance with the latter authors, we could neither cast nor dissect out any vascular connections between the adrenal gland and kidney.

In our previous casting of the vascular bed of the extra-adrenal chromaffin body, a circular constriction probably representing an endothelial cushion or sphincter was constantly imprinted at the origin of the afferent vessel of the extra-adrenal chromaffin body (MURAKAMI et al., 1988a). In the present specimens, however, such a constriction could not be found. This may be due to the full injection of resin, which makes such an impression of endothelial cushion or sphincter unclear.

The present paper proves that the cationic iron colloid/polyethylene glycol/tannin/osmium-impregna- 
tion (OHTSUKa and MuraKami, 1988) is useful for scanning electron microscopy of biological specimens; it markedly reduces tissue shrinkage during dehydration and drying, and also preserves the delicate tissue structures from these treatments. As described above, the diameters of the endothelial fenestrations of the cationic iron colloid/polyethylene glycol/tannin/osmium-impregnated cortical capillaries and medullary veins were constantly $40-50 \mathrm{~nm}$. These values almost correspond to those $(50 \mathrm{~nm})$ as estimated by transmission electron microscopy of epoxy resin-embedded specimens (KIKUTA and MURAKAMI, $1984)$, and are less than those $(50-100 \mathrm{~nm})$ as measured by scanning electron microscopy of solely tannin/ osmium-impregnated specimens (MOTTA et al., 1979).

More strictly, the cationic iron colloid/polyethylene glycol/tannin/osmium-impregnation has an advantage over the previous fixation or impregnation methods in that it reinforces the vascular endothelium as well as the other tissue elements and allows a clear scanning demonstration even of such labile endothelial fenestrations as those of the medullary veins. Our preliminary experiments in this study have shown that in the solely tannin/osmium-impregnated specimens, the fenestrations of the medullary veins are observed as obscurely delineated slight concaves, which might be usually overlooked (MOTTA et al., 1979). Our preliminary experiments have also shown that in the simply glutaraldehyde-or glutaraldehyde/ osmium tetroxide-fixed specimens with neither impregnation nor reinforcement, the fenestrations of the medullary veins are not visible in the scanning electron microscope even when the specimens are freeze-dried. This may be due to the marked shrinkage or extensive flattening of endothelial components delineating the fenestrations. In contrast to these labile fenestrations of the medullary veins, the fenestrations of the cortical capillaries, like those of the liver sinusoids and kidney glomerular capillaries, are constantly and clearly visible in the scanning electron microscope even when the tannin/osmium- or cationic iron colloid/polyethylene glycol/tannin/ osmium-impregnation is omitted. In these simple preparations, however, the fenestrations of the cortical capillaries are markedly expanded and their diameters are $100 \mathrm{~nm}$ or wider. These values are much more than those as estimated in the reinforced specimens and also those as measured by transmission electron microscopy of epoxy resin-embedded specimens (see above).

\section{REFERENCES}

Bachmann, R.: Die Entwicklung der Nebenniere der Säuger. In: (ed. by) R. BACHMANN and B. SCHARRER: Möllendorff's Handbuch der mikroskopischen Anatomie des Menschen, VI/5. Springer-Verlag, Berlin, 1954a (p. 117-146).

-: Beizwischennieren (akzessorische Rindenknötchen), Rindenadenome. In: Ibidem, 1954b (p. 264-275).

BennetT, H. S. and L. Kilham: The blood vessels of the adrenal gland of the adult cat. Anat. Rec. 77: 447-471 (1940).

Coupland, R. E.: The post-natal distribution of the abdominal chromaffin tissue in the guinea-pig, mouse and white rat. J. Anat. 94: 244-256 (1960).

- Blood supply of the adrenal gland. In: (ed. by) H. BRASChKo, G. SAYERS and A. D. SMITH: Handbook of physiology, Section 7, Endocrinology. American Physiology Society, Washington, 1975 (p. 283-294).

Coupland, R. E. and J. D. B. MacDougall: Adrenaline formation in noradrenaline-storing chromaffin cells in vitro induced by corticosterone. J. Endocrinol. 36: 317324 (1966).

Coupland, R. E. and J. E. Selby: The blood supply of the mammalian adrenal medulla: A comparative study. J. Anat. 122: 539-551 (1976).

Dempster, W. J.: The nature of the venous systems in the adrenal gland. Tohoku J. Exp. Med. 112: 63-77 (1974).

EzAKI, T.: Ein Studium über den Blutversorgungsplan der Nebenniere von der Maus (In Japanese). Kurume Igakukai Z. 21: 1322-1339 (1958).

FAWCETT, D. W.: Adrenal glands and paraganglia. In: (ed. by) D. W. FAWCETT: A textbook of histology. 11th ed., W. B. Saunders Co., Philadelphia-London-Torontoetc., 1986 (p. 516-534).

Flint, J. M.: The blood-vessels, angiogenesis, organogenesis, reticulum, and histology of the adrenal. Johns Hopkins Hosp. Rep. 9: 153-229 (1900).

GARDNER, L. I.: Development of the normal fetal and neonatal adrenal. In: (ed. by) L. I. GARDNER: Endocrine and genetic diseases of childhood and adolescence. 2nd ed., W. B. Saunders Co., Philadelphia, 1975 (p. 460-476).

Gersh, I. and A. Grollman: The vascular pattern of the adrenal gland of the mouse and rat and its physiological response to changes in glandular activity. Contrib. Embryol. Carnegie Inst. 29: 113-125 (1941).

Harrison, R. G. and M. J. HoEY: The anatomy of adrenal vascularization. In: (ed. by) R. G. HARRISON and M. J. HOEY: The adrenal circulation. Blackwell Scientific Publications, Oxford, 1960 (p. 9-23).

HAyAShI, T.: Studies on the vascular supplies of the adrenals (In Japanese with English abstract). Fukuoka Igaku Z. 50: 2846-2861 (1959).

Henderson, J. R. and P. M. DAniel: Portal circulations and their relation to countercurrent systems. Quart. J. Exp. Physiol. 63: 355-369 (1978). 
Hervonen, A.: Development of catecholamine-storing cells in human fetal paraganglia and adrenal medulla. A histochemical and electron microscopical study. Acta Physiol. Scand. 83 (Suppl. 368): 1-94 (1971).

Hervonen, A., S. Partanen, A. VaAlasti, M. Partanen, L. KAVERVA and H. Alho: The distribution and endocrine nature of the abdominal paraganglia of adult man. Amer. J. Anat. 153: 563-572 (1978).

HoraceK, M. J., A. M. Earle and J. P. Gilmore: An investigation of potential vascular connections between the kidney and the adrenal gland. Acta Anat. 123: 9-13 (1985).

IIDA, N.: Freeze-fracture of biological specimens prior to conductive staining. Arch. Histol. Jap. 47: 79-99 (1984).

Inoué, T. and H. Osatake: A new drying method of biological specimens for scanning electron microscopy: the t-butyl alcohol freeze-drying method. Arch. Histol. Cytol. 51: 53-59 (1988).

Katholi, R. E., K. ImamuRa and T. N. James: Histologic and fine-structural anatomy of the adrenorenal portal vessels in the dog. Amer. J. Anat. 165: 249-260 (1982).

Keene, A. and E. E. Hewer: Observations on the development of the human suprarenal gland. J. Anat. 61:302324 (1927).

Kikuta, A. and T. Murakami: Microcirculation of the rat adrenal gland: a scanning electron microscope study of vascular casts. Amer. J. Anat. 164: 19-28 (1982).

-: Relationship between chromaffin cells and blood vessels in rat adrenal medulla: a transmission electron microscopic study combined with blood vessel reconstructions. Amer. J. Anat. 170: 73-81 (1984).

LEVER, J. D.: Observations on the adrenal blood vessels in the rat. J. Anat. 86: 459-467 (1952).

MaRTin, C. R.: Catecholamines, serotonin and related regulators. In: (ed. by) C. R. MARTIN : Endocrine physiology. Oxford University Press, New York-London, 1985 (p. 270-318).

Mascorro, J. A., A. Hervonen and R. D. Yates: Extraadrenal chromaffin organs (abdominal paraganglia): Distribution, histology and fine structure. In: (ed. by) P. M. MotTA: Ultrastructure of endocrine cells and tissues. Martinus Nijhoff Publishers, Boston-The HagueDordrecht-Lancaster, 1984 (p. 180-188).

MotTa, P., M. Muto and T. Fujita: Three dimensional organization of mammalian adrenal cortex. A scanning electron microscopic study. Cell Tiss. Res. 196: 23-38 (1979).

MuraKaMi, T.: Pliable methacrylate casts of blood vessels: use in a scanning electron microscope study of the microcirculation in rat hypophysis. Arch. Histol. Jap. 38: 151-168 (1975a).

- Injection replica/scanning electron microscope method, and its use in an analysis of the vascular arrangements of the adrenal gland (In Japanese). Seitai no Kagaku 26: 453-456 (1975b).

Murakami, T., O. Ohtani, A. Ohtsuka and A. Kikuta: Injection replication and scanning electron microscopy of blood vessels. In (ed. by) G. M. HodGEs and K. E. CARR: Biomedical research applications of scanning electron microscopy, Vol. 3. Academic Press, London, 1983 (p. 1-30).

Murakami, T., M. Horie, T. Taguchi, A. Kikuta and A. OHTSUKA: The blood vascular architecture of the extra-adrenal chromaffin body in the adult rat: a scanning electron microscopic study of corrosion casts. Arch. Histol. Cytol. 51: 147-158 (1988a).

Murakami, T., C. Yamamoto, A. Ohtsuka. A. Kikuta and T. TAGUCHI: Blood vascular architecture of the rat extra-adrenal cortical body: a scanning electron microscopic study of corrosion casts. Arch. Histol. Cytol. 51: 263-270 (1988b).

Ohtsuka, A. and T. Murakami: Iron-polyethylene glycol impregnation: an attempt to reduce shrinkage of specimens in SEM preparation. Scanning 10: 177-182 (1988).

OKano, H., Y. OHTA, H. SAWA and I. Fujiwara : Cubical anatomy of several ducts and vessels by injection method of acrylic resin. IX. On the vascular system of the suprarenel gland in dog and cat. Okajimas Fol. Anat. Jap. 34: 553-570 (1960).

Pohorecky, L. A. and R. J. Wurtman: Adrenocortical control of epinephrine synthesis. Pharmacol. Rev. 23: 135 (1971).

Russo, E. and G. V. Pelagalli: Macro- et microcirculation des glandes surénales chez les petits ruminants. Recherches effectuées sur les espèces ovines et caprines. Acta Anat. 82: 179-197 (1972).

WheEler, E. E., J. B. GAVIN and R. N. Seelye: Freezedrying from tertiary butanol in the preparation of endocardium for scanning electron microscopy. Stain Technol. 50: 331-337 (1975).

W AtzkA, M.: Die Paraganglien. In: (ed. by) W. BARG MANn, T. Hellman and M. WATZKA: Möllendorff's Handbuch der mikroskopischen Anatomie des Menschen, VI/4. Springer-Verlag, Berlin, 1943 (p. 262-308).

WRETE, M.: Beiträge zur Kenntnis von der Entwicklung des chromaffinen Gewebes der Bauchregion beim Menschen. Z. Mikrosk.-Anat. Forsch. 9: 79-98 (1927).

Wurtman, R. J. and J. Axelrod: Control of enzymatic synthesis of adrenaline in the adrenal medulla by adrenal cortical steroids. J. Biol. Chem. 241: 2301-2305 (1966). 